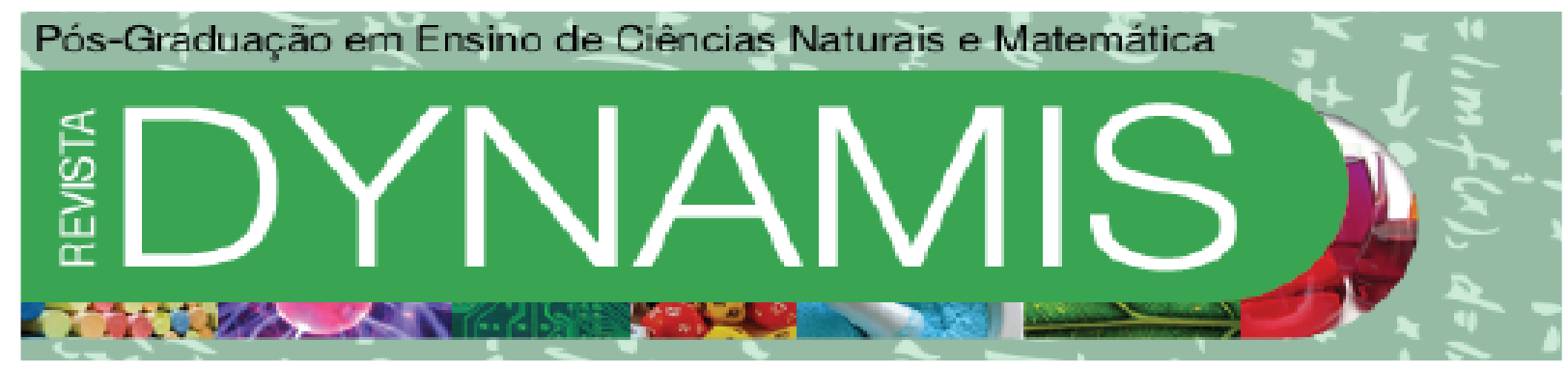

\title{
PROBLEMATIZANDO EXPERIÊNCIAS DE MODELAGEM MATEMÁTICA DESENVOLVIDAS NO ENSINO MÉDIO
}

Problematizing experiences of mathematical modeling developed in high school

Márcia Jussara Hepp Rehfeldt

Doutora em Informática na Educação

Universidade do Vale do Taquari - UNIVATES

mrehfeld@univates.br

Italo Gabriel Neide

Doutor em Física

Universidade do Vale do Taquari - UNIVATES

Ítalo.neide@univates.br

Wolmir José Böckel

Doutor em Química

Universidade do Vale do Taquari - UNIVATES

wjbockerl@univates.br

Rosilene Inês König

Mestre em Ensino de Ciências Exatas

Universidade do Vale do Taquari - UNIVATES

rosilene@universo.univates.br

Camila Haefliger

Graduanda em Engenharia Civil

Universidade do Vale do Taquari - UNIVATES

cahaefliger@yahoo.com.br 


\title{
Resumo
}

Este relato tem por intuito apresentar resultados obtidos a partir da exploração de uma atividade de Modelagem Matemática acerca da água desenvolvida com alunos do $1^{\circ}$ ano do Ensino Médio de uma escola localizada no interior do RS. O planejamento ocorreu entre uma professora de Matemática da Escola Básica, integrantes da Pesquisa Tendências no Ensino e bolsistas de Iniciação Científica. $\mathrm{O}$ grupo se reuniu quinzenalmente durante dois meses. A prática de Modelagem Matemática foi planejada à luz dos passos de Burak (2004). O papel da professora titular foi o de mediadora nos processos de ensino e de aprendizagem, estimulando a autonomia dos alunos. Os resultados apontam que nem todos os alunos conseguiram realizar registros matemáticos. Entretanto, entre os que os realizaram, pôde-se observar tabelas, maquetes, gráficos, quadros e uma equação expressa oralmente. Segundo os alunos, a prática revelou o quanto a exploração da proposta contribuiu no entendimento de aspectos relacionados à água, tais como desperdício, custos, tratamento, localização de poços, entre outros. Os alunos afirmaram que foi relevante aprender matemática de forma contextualizada, utilizando temas da sua realidade e que foram corresponsáveis pela sua aprendizagem. Por fim, aludem que desenvolveram a capacidade de colaborar com os colegas, trabalhando em pequenos grupos.

Palavras-Chave: Modelagem Matemática. Ensino Médio Politécnico. Água.

\begin{abstract}
This study aims to present results obtained from the exploration of a Mathematical Modeling activity about water developed with students of the 1st year of High School from RS state. The planning was carried out jointly between a high school mathematics teacher, members of the Trends in Education Survey and scholarships. The group met fortnightly for two months. The practice of Mathematical Modeling was planned in the light of the steps of Burak (2004). The role of the teacher was the guide in the teaching and learning processes, stimulating the students' autonomy. The results show that not all students were able to make mathematical records of their problem situations described. However, among those who performed them, it was possible to observe tables, models, graphs, tables and an equation expressed orally. According to the students, the practice revealed how much the exploration of the proposal contributed to the understanding of aspects related to water, such as water waste, costs, treatment, location of wells, among others. The students expressed that it was relevant to learn mathematics in a contextualized way, using themes of their reality and that were co-responsible for their learning. Finally, they mention that they have developed the ability to collaborate with colleagues, working in small groups.
\end{abstract}

Keywords: Mathematical Modeling. Polytechnic High School. Water 


\title{
1 INTRODUÇÃO
}

A busca por uma forma diferenciada de ensinar Matemática é cada vez mais almejada por professores, uma vez que os alunos anseiam por aulas mais contextualizadas, criativas e relacionadas à sua realidade (ALMEIDA, SILVA e VERTUAN, 2013; BIEMBENGUT e HEIN, 2003; BASSANEZI, 2015). Com o intuito de transpor a barreira do ensino tradicional (BASSANEZI, 2015) e primando por processos de ensino capazes de promover a criatividade, a criticidade e o desenvolvimento do pensamento crítico, desenvolvemos a pesquisa intitulada "Tendências no Ensino". Esta tem como objetivos fomentar e explorar diferentes tendências que possam auxiliar no processo de ensino da Matemática; analisar as dificuldades e potencialidades do uso de diferentes tendências em sala de aula; estruturar, explorar e discutir propostas de ensino. Uma das tendências estudadas e foco do presente trabalho é a Modelagem Matemática.

De acordo com Bassanezi (2015, p. 15), a Modelagem Matemática "é uma estratégia utilizada para obtermos alguma explicação ou entendimento de determinadas situações reais". De forma similar, Almeida, Silva e Vertuan (2013) conceituam a Modelagem Matemática como um conjunto de procedimentos que são implementados em uma situação real e por meio dos quais se consegue expressar a solução do problema. Para Biembengut (2014) e Almeida, Silva e Vertuan (2013), essa solução pode ser expressa de diferentes formas, entre elas gráficos, tabelas, maquetes, quadros, entre outros. Barbosa (2001, p. 2) por sua vez cita que a modelagem é "um ambiente de aprendizagem no qual os alunos são convidados a indagar e/ou investigar, por meio da matemática, situações oriundas de outras áreas da realidade".

Ao conceito de Modelagem Matemática, que tem similaridades às anteriormente apresentadas, Klüber e Burak (2008, p. 20) acrescentam dois princípios, com base na interação pelo diálogo, que também foram levados em consideração neste estudo, quais sejam: "1) o interesse do grupo; e 2) a obtenção de informações e dados do ambiente, onde se encontra o interesse do grupo".

Entendemos, assim como Burak e Aragão (2012, p. 85, grifos nossos), que

\begin{abstract}
Não pretendemos formar sujeitos sem determinação, sem ideias próprias, sem capacidade de argumentar e dialogar sobre uma situação, não pretendemos formar um sujeito incapaz de decidir por si, sem possibilidade de antever uma situação, sem noção do global. Ao contrário, intencionamos formar um cidadão que desenvolva a autonomia e seja crítico, capaz de trabalhar em grupo, capaz de tomar decisões diante das situações do cotidiano, da sua vida familiar, da sua vida profissional ou sua condição de cidadão, um sujeito capaz de promover transformações em sua comunidade.
\end{abstract}

As palavras grifadas na citação acima também são encontradas no documento que rege o Ensino Médio Politécnico, implementado nas escolas públicas do Rio Grande do Sul, ao qual pertencente a escola onde foi desenvolvida esta prática. Neste documento está expresso, entre outros aspectos, que os objetivos do ensino, devem contribuir para o exercício pleno da cidadania e fornecer aos alunos meios para progredir no trabalho; qualificar o estudante no desenvolvimento da autonomia intelectual, do pensamento crítico e dos fundamentos

ISSN 1982-4866. Revista Dynamis. FURB, Blumenau, v. 24, n.1, p.77-93, 2018. 
científicos e tecnológicos; desenvolver ações que possibilitem ao aluno integrar-se na comunidade, tornando-se mais atuante nas práticas sociais, respeitando a diversidade (RS/SE,2011).

Também Barbosa (2008, p. 50), ao falar da perspectiva sociocrítica afirma que os alunos precisam ler os modelos matemáticos de forma crítica "analisando como os resultados matemáticos dependem do lugar de onde eles são produzidos e como estes últimos são usados (Por quem são produzidos? Que resultados geram na sociedade? A quem beneficia? A quem prejudica?).

Refletindo ainda acerca das motivações da inserção de Modelagem Matemática entendemos, assim como Almeida e Brito (2005), que essa metodologia é uma alternativa pedagógica que pode favorecer uma aproximação da matemática escolar com determinados problemas extraescolares que são vivenciados pelos alunos. Segundo os autores (ibidem), atividades desenvolvidas por meio da Modelagem Matemática podem contribuir para o estabelecimento de diálogos entre os envolvidos nos processos de ensino e de aprendizagem, privilegiando o interesse dos alunos.

Assim, no sentido de tornar o aluno mais presente neste processo, bem como ilustrar aos professores como desenvolver uma prática de Modelagem Matemática Burak (2004) propõe cinco etapas: 1) Escolha do tema - os alunos podem mencionar temas de interesse ou uma situação-problema a ser resolvida. Nesta etapa o professor poderá auxiliar os alunos no processo de escolha e encaminhamento; 2) Pesquisa exploratória - os alunos poderão conhecer melhor a questão a ser pesquisada, tomando conhecimento de informações disponíveis; 3) Levantamento de problemas - onde os alunos formulam matematicamente os problemas a partir dos dados coletados anteriormente; 4) Resolução dos problemas e desenvolvimento dos conteúdos no contexto do tema - os conteúdos matemáticos recebem significados, em especial pela ação mediadora do professor; 5) Análise crítica da(s) solução(ões) - neste momento se analisa e discute os resultados encontrados por meio da socialização e interação entre os alunos.

De acordo com Klüber e Burak (2008, p. 22), as cinco etapas propostas são desenvolvidas ocorrendo uma interação entre três elementos (FIGURA 1): "professor-aluno-ambiente, sem a predominância de um ou de outro, valendo-se, porém, da interação entre as três dimensões, porque o aluno deve buscar, o professor deve mediar e o ambiente é a fonte de toda a pesquisa".

\section{Figura 1 - Proposta de interação entre professor, aluno e ambiente no desenvolvimento de uma prática de Modelagem Matemática}

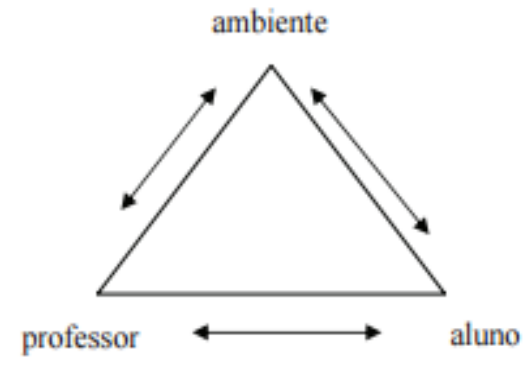

Fonte: Klüber e Burak (2008, p. 22)

ISSN 1982-4866. Revista Dynamis. FURB, Blumenau, v. 24, n.1, p.77-93, 2018. 
Ainda para os autores, "isso reafirma as influências dos pressupostos da etnografia, a qual procura compreender o ambiente e os sujeitos para interpretar o material de investigação coletado e, posteriormente, trabalhar com as variáveis que surgiram no processo" (KLÜBER; BURAK, 2008, p. 22).

Já Barbosa (2001, p. 2) explicita outra forma de realizar uma prática de Modelagem Matemática, descrevendo diferentes níveis, a saber:

\begin{abstract}
Nível 1 - Trata-se da problematização de algum episódio real. A uma dada situação, associam-se problemas. A partir das informações qualitativas e quantitativas apresentadas no texto da situação, o aluno desenvolve a investigação do problema proposto.

Nível 2 - O professor apresenta um problema aplicado, mas os dados são coletados pelos próprios alunos durante o processo de investigação.

Nível 3 - A partir de um tema gerador, os alunos coletam informações qualitativas e quantitativas, formulam e solucionam problemas.
\end{abstract}

Assim, entendemos que existem diferentes formas de explorar práticas de Modelagem Matemática e a experiência de cada professor ou aluno pode interferir nas percepções desse processo. Ainda percebe-se que há professores com pouca experiência e outros com mais tempo de investigação. À medida que vão explorando a Matemática por meio da modelagem, mais confiantes se tornam. Neste sentido, Barbosa (2001, p. 4) afirma que "parece que os professores perceberam a necessidade de desenvolver conhecimentos diversos daqueles que vinham utilizando e, para isto, sentiram a necessidade de convivência mais prolongada com a Modelagem", ou seja, é necessário experiência e vivência para poder explorar atividades por meio da Modelagem Matemática. Entretanto, ao mesmo tempo em que os professores sabem da importância de desenvolver atividades, a partir da Modelagem Matemática, há ainda uma moderação quanto à exploração desta metodologia em sala de aula. Conforme Barbosa (2001, p. 4):

[...] os professores acreditavam que a Modelagem confere maior significado às atividades escolares, propicia envolvimento dos alunos, promove melhor relacionamento e influi positivamente no desempenho escolar. Por outro lado, sublinhavam sua insegurança em continuar utilizando Modelagem em suas aulas e com a reação de outros atores da escola (os colegas de trabalho, os diretores, os pais, os alunos). Os professores verbalizaram seu próprio "despreparo" para desenvolver atividades desta natureza e assinalaram que a continuidade da aplicação da Modelagem é a forma adequada de adquirir experiência, segurança e confiança.

Blum e Ferri (2009) e Silva e Dalto (2011) também corroboram afirmando que a prática com Modelagem Matemática é eventualmente utilizada. Tal fato nos remete a necessidade de ampliar a exploração de práticas de Modelagem Matemática, assim como a preparação de nossos professores para tal atividade.

De acordo com Barbosa (2001), alguns estudos indicam que os professores possuem cautela e sentem-se tensos quando exploram temáticas por meio da Modelagem Matemática. Porém, ao mesmo tempo em que eles sustentavam dificuldades na implementação desta, também defendiam esta abordagem. As vantagens assinaladas pelos professores foram

ISSN 1982-4866. Revista Dynamis. FURB, Blumenau, v. 24, n.1, p.77-93, 2018. 
[...] que a Modelagem contribui na compreensão dos conceitos matemáticos, desenvolve habilidades de pesquisa e experimentação, leva em conta o contexto sóciocultural e, por fim, viabiliza a interdisciplinaridade e a espiralização do currículo. Ao falar dos obstáculos, os professores citam os programas pré-estruturados, os pais, a burocracia educacional e os próprios alunos (BARBOSA, 2001, p. 3-4).

À luz desses referenciais mencionados, tais como as etapas de Burak (2004), dos níveis propostos por Barbosa (2001) e dos objetivos propostos no documento que regula o Ensino Médio Politécnico, organizamos uma prática de Modelagem Matemática, a qual relatamos a seguir. Desta forma, o objetivo deste artigo é ilustrar como um grupo de 26 alunos desenvolveu, sob orientação de uma professora da Escola Básica, uma atividade de Modelagem Matemática, tendo como mote de discussões o tema Água, escolhido pelos próprios alunos. A referida professora é graduada em Ciências Exatas e cursou o Mestrado em Ensino de Ciências Exatas. Ainda não tinha experiência em Modelagem Matemática, mas encontrava-se motivada para realizar atividades diferenciadas, inserindo-se na pesquisa como voluntária. Como egressa do mestrado profissional, já havia desenvolvido outras práticas diferenciadas.

\section{METODOLOGIA}

Este estudo caracteriza-se como sendo de cunho qualitativo, tendo em vista a investigação das características dos indivíduos e cenários que não podem ser facilmente representados numericamente, onde os dados foram verbais, sendo coletados por meio da observação, descrição e gravação (MOREIRA e CALEFFE, 2008).

Quanto aos procedimentos técnicos, compreende-se ser um estudo de caso, pois segundo Goldenberg (2013, p. 33-34):

[...] não é uma técnica específica, mas uma análise holística, a mais completa possível, que considera a unidade social estudada como um todo, seja um indivíduo, uma família, uma instituição, uma comunidade, com o objetivo de compreendê-los em seus próprios termos. O estudo de caso reúne o maior número de informações detalhadas, por meio de diferentes técnicas de pesquisa, com o objetivo de apreender a totalidade de uma situação e descrever a complexidade de um caso concreto.

À luz desses referenciais, a prática pedagógica foi desenvolvida com uma turma de alunos do primeiro ano do Ensino Médio Politécnico ${ }^{1}$ de uma escola estadual situada no interior do Rio Grande do Sul, composta por 16 meninas e 10 meninos, na faixa etária de 15 anos. O educandário, único do município que oferece o Ensino Médio para sua população, é frequentado por alunos oriundos da zona urbana e rural.

\footnotetext{
${ }^{1}$ O Ensino Médio Politécnico é "aquele em que na prática pedagógica ocorre a permanente instrumentalização dos educandos quanto a compreensão do significado da ciência, das letras e das artes; do processo histórico de transformação da sociedade e da cultura como instrumento de comunicação, acesso ao conhecimento e do exercício da cidadania" (RS/SE, 2012, p. 8).
} 
A proposta de desenvolvimento de uma prática de Modelagem Matemática iniciou a partir de um diagnóstico com os alunos da referida turma sobre alguns temas relacionados a problemas sociais que eles gostariam de estudar. Burak (2004) sugere que uma prática de Modelagem Matemática inicie pela escolha do tema, sendo que isso pode ser realizado conjuntamente pelos alunos e o professor. Assim, emergiram reflexões sobre assuntos tais como: acessibilidade no centro da cidade, pavimentação das estradas do interior do município e qualidade e distribuição da água à população. Dentre os temas sugeridos pelos alunos para realizar o estudo, a maioria demonstrou interesse pelo último tema, alegando que existem muitos fatores alusivos à água a serem investigados.

A partir desse tema, os alunos foram divididos em pequenos grupos, como sugere Burak (2004), sendo que cada grupo pesquisou um subtema diferente. Entre os subtemas constaram: Sistemas de rede de água, Desperdício de água, Crosta branca: saúde e riscos à saúde pública, Localização e perfuração de novos poços, Funcionamento e utilidade das bitolas, Recolhimento e reaproveitamento da água, Custos da água, Doenças transmitidas pela água e Tratamento da água.

A prática foi realizada no decorrer de três meses, durante as aulas de Matemática, sendo que a professora titular utilizou de um a dois períodos semanais de cinquenta minutos, cada. No primeiro momento, diante do subtema selecionado, os grupos traçaram alguns objetivos a serem alcançados durante o estudo, assim como curiosidades acerca do assunto. Em seguida, buscaram informações sobre a temática em livros, sites e agendaram entrevistas em órgãos governamentais e com pessoas da comunidade na qual estão inseridos. Para Burak (2004), a pesquisa exploratória é o segundo passo de uma Modelagem Matemática, sendo que esta tem por objetivo conhecer melhor o tema em questão, com vistas a tornar o aluno mais crítico e atento às informações.

Em especial, o grupo incumbido pelo estudo sobre a formação da crosta branca nos utensílios domésticos, como, por exemplo, nas chaleiras, com o auxílio da professora titular, solicitou uma explanação referente ao subtema. Para tanto, todos os alunos participaram de uma atividade desenvolvida no Laboratório de Química da instituição de ensino superior em que o grupo de pesquisa atua, sendo desafiados pelo pesquisador da área da Química e integrante da pesquisa, a realizar um experimento para compreender como se forma esta crosta. Organizados em grupos, realizaram uma experiência que avaliou a concentração de carbonato de sódio na água numa solução saturada, em relação à temperatura e resfriamento da solução.

As demais atividades realizadas em grupo ocorreram na escola ou na cidade onde se localiza o educandário. No decorrer do estudo, os grupos de alunos registraram detalhadamente as atividades desenvolvidas em um diário de bordo, seguindo os passos três e quatro sugeridos por Burak (2004) que consistem, respectivamente, no levantamento de problemas, que é a formulação matemática dos problemas e a resolução destes, oriundos dos dados coletados anteriormente e o desenvolvimento dos conteúdos no contexto do tema. Esta última etapa consiste no uso de conteúdos matemáticos e que requer maior orientação do professor.

O papel da professora titular foi o de mediadora no processo de aprendizagem dos alunos. De acordo com Almeida, Silva e Vertuan (2013, p. 24),

[...] orientar é indicar caminhos, é fazer perguntas, é não aceitar o que não está bom, é sugerir procedimentos; orientar não é dar respostas prontas e acabadas, orientar não é sinalizar vale-tudo; orientar não é esperar que o aluno simplesmente siga exemplos; orientar não é livrar-se de estudar, de se preparar para o exercício de função; orientar não é despir-se da autoridade de professor. 
Para ilustrar os resultados obtidos, os alunos construíram maquetes e elaboraram um relatório contendo as informações sobre o estudo realizado. Ao final do estudo, os grupos compartilharam seus resultados. Para analisar esses resultados obtidos, os pesquisadores se deslocaram até a escola e contemplaram as apresentações dos alunos. Neste momento, a professora titular também esteve presente e todos problematizaram os resultados obtidos. De acordo com Burak (2004), o último passo de uma Modelagem Matemática é a análise crítica das soluções, ou seja, nesta fase são analisados e discutidos os resultados encontrados. Este momento é importante, pois ocorrem a socialização dos resultados e a interação entre os alunos e o professor. Para sintetizar os passos acima mencionados apresentamos o Quadro 1.

Quadro 1 - Síntese das etapas desenvolvidas desde a coleta de dados e a apresentação dos resultados pelos nove grupos de alunos

\begin{tabular}{|c|c|c|c|c|c|c|}
\hline \multirow[b]{2}{*}{ Grupos } & \multicolumn{2}{|c|}{ Coleta de dados } & \multicolumn{4}{|c|}{ Forma de apresentação dos resultados } \\
\hline & $\begin{array}{l}\text { Pesquisa em } \\
\text { sites }\end{array}$ & Entrevista & $\begin{array}{c}\text { Dados } \\
\text { numéricos* }\end{array}$ & Gráfico & Experimento & Cálculos \\
\hline G1 & $\mathrm{x}$ & $\mathrm{x}$ & $\mathrm{x}$ & $\mathrm{x}$ & $\begin{array}{c}\mathrm{x} \\
\text { (maquete) }\end{array}$ & $\mathrm{X}$ \\
\hline $\mathrm{G} 2$ & $\mathrm{x}$ & $\mathrm{x}$ & $\mathrm{x}$ & & $\begin{array}{c}\mathrm{X} \\
\text { (chuveiro) }\end{array}$ & $\mathrm{X}$ \\
\hline G3 & $\mathrm{x}$ & $\mathrm{x}$ & $\mathrm{x}$ & & x (laboratório) & \\
\hline G4 & $\mathrm{x}$ & $\mathrm{x}$ & $\mathrm{x}$ & & $\begin{array}{c}\mathrm{x} \\
\text { (maquete) }\end{array}$ & \\
\hline G5 & $\mathrm{x}$ & $\mathrm{x}$ & $\mathrm{x}$ & & & \\
\hline G6 & $\mathrm{x}$ & $\mathrm{x}$ & & & & \\
\hline G7 & $\mathrm{x}$ & $\mathrm{x}$ & $\mathrm{x}$ & & & \\
\hline G8 & $\mathrm{x}$ & $\mathrm{x}$ & $\mathrm{x}$ & & & \\
\hline G9 & $\mathrm{x}$ & $\mathrm{x}$ & & & & \\
\hline
\end{tabular}

*dados numéricos - referem-se a informações sem envolvimento de cálculo.

Fonte: Autores do artigo, 2016.

Para elucidar, a indicação do X sugere a ocorrência de determinado fato. Por exemplo, o grupo 1 efetivou uma pesquisa em sites, realizou entrevistas, apresentou dados no trabalho em números, demonstrou resultados por meio de gráfico, desenvolveu um experimento e realizou cálculos.

Cabe salientar ainda que, no decorrer das práticas, a professora registrou as atividades em áudio, vídeo e foto, sendo estas posteriormente transcritas pelos bolsistas de iniciação científica e os dados analisados pelo grupo de pesquisadores, em conjunto com a professora titular. Ao término das atividades, os alunos responderam um questionário, que teve como objetivo verificar a opinião dos alunos e investigar quais as implicações oriundas provenientes das atividades desenvolvidas. Os resultados estão descritos a seguir. 


\section{ANÁLISE E DISCUSSÃO DOS DADOS}

A análise dos dados será descrita de acordo com o que cada um dos nove grupos de alunos desenvolveu, encontrou ou procurou compreender.

O primeiro grupo escolheu como subtema "Sistemas de redes de distribuição de água". Para desenvolver seu estudo realizaram uma coleta de dados quanto ao número de novas ligações de abastecimento de água que são feitas a cada ano, em residências ou estabelecimentos concluindo que entre os anos de 2010 e 2015 foram feitos, em média, 97,16 novos registros anuais. Com esses dados os alunos elaboraram o Gráfico a seguir (Figura 2).

\section{Figura 2 - Número de ligações de redes de abastecimento realizadas na cidade}

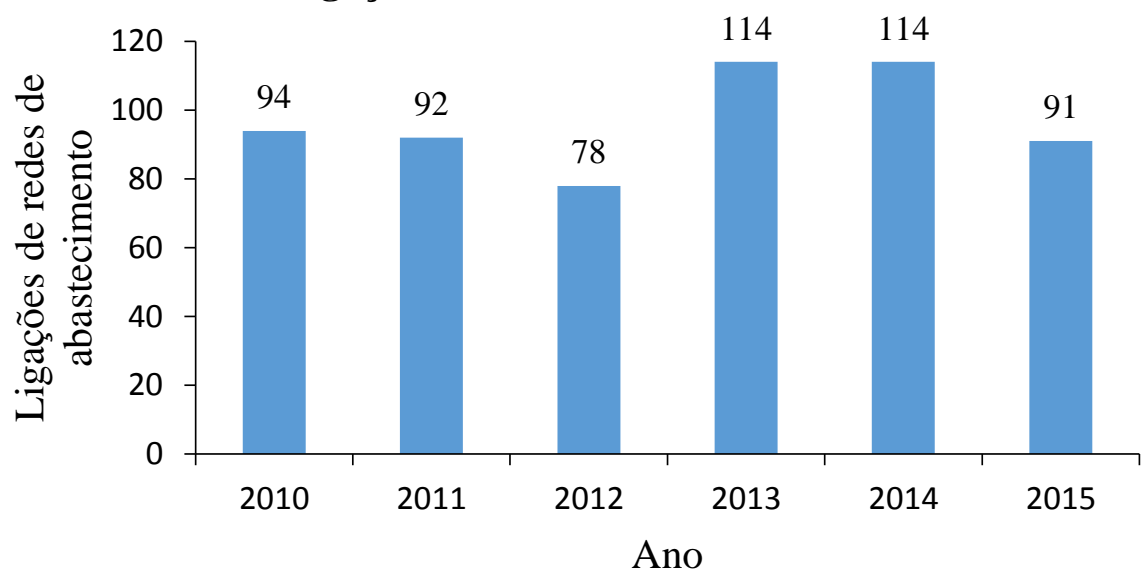

Fonte: Grupo 1, 2016

Também coletaram informações junto à prefeitura municipal acerca do número de reservatórios existentes na cidade, concluindo que são 28 reservatórios, sendo 23 com capacidade para 20 mil litros, um de 120 mil litros, um de 170 mil litros e dois com capacidade de 15 mil litros.

Além disso, na entrevista com um funcionário da prefeitura municipal foram informados de como é feita a limpeza dos reservatórios e com que frequência o conserto dos canos é realizado, bem como os problemas mais frequentes relacionados à rede de distribuição, à quantidade de residências e prédios ligados a cada poço artesiano, entre outros. Para finalizar as atividades, o grupo elaborou uma maquete, a qual representa a rede de distribuição de água de seu município, sendo ela ramificada, com seus condutos primários e secundários (FIGURA $2)$. 


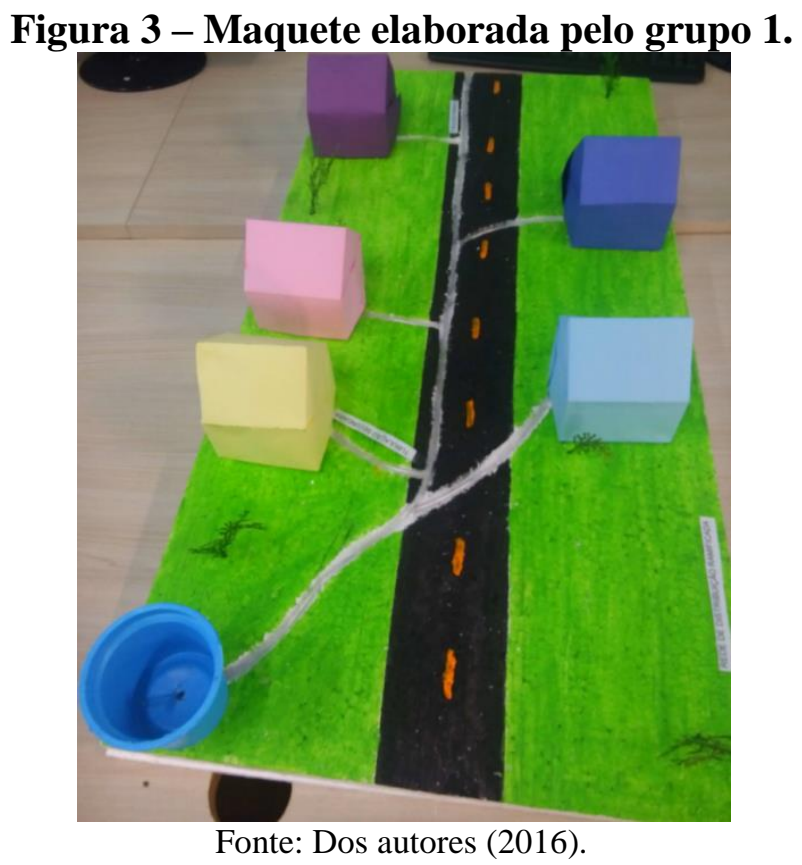

Ao finalizarem a pesquisa os alunos comentaram que:

[...] compreendemos o funcionamento e a importância das redes de distribuição de água para a nossa qualidade de vida, afinal, elas são responsáveis por abastecer nossas casas com uma das maiores riquezas da natureza, a água. A pesquisa nos acrescentou muito conhecimento e experiências, sobre algo que pouco entendíamos (GRUPO 1).

Ao analisar o relatório do grupo pôde-se observar a emergência de modelos na forma de maquete, tabelas e desenhos dos diferentes tipos de reservatórios. Os resultados obtidos estão em consonância com o que afirma Biembengut (2014) acerca de um modelo matemático. Segundo a autora, ele pode ser um conjunto de representações, entre elas, uma imagem, um desenho, um projeto, um esquema, um gráfico ou uma lei matemática. Deve-se considerar que "nenhum modelo ou forma de representar é casual ou rudimentar. É, antes, a expressão das percepções da realidade, do desejo da aplicação, da representação" (BIEMBENGUT, 2014, p. 201).

O segundo grupo investigou o desperdício de água e suas consequências. Com os dados obtidos de pesquisas na internet o grupo constatou que, em números, esse desperdício é equivalente a $41 \%$ de toda água tratada no Brasil. Dentre exemplos de ocorrência de desperdício, comentaram que a maior perda de água ocorre nos sistemas de abastecimento devido a falhas técnicas nas tubulações e nos sistemas públicos.

Em adição, os integrantes realizaram uma entrevista com um funcionário da prefeitura, concluindo que no mês de novembro de 2015 foram consumidos $22.631 \mathrm{~m}^{3}$ de água e que praticamente todos os dias houve vazamentos nas tubulações. Para finalizar o estudo acerca do desperdício, realizaram uma comparação de gastos de litros de água no banho dos integrantes do grupo: "Aluno 1 - gastou 60 litros de água tomando seu banho por 10 minutos; Aluno 2 usou 135 litros no decorrer de 15 minutos e Aluno 3 - consumiu 22,5 litros em 5 minutos". Segundo os componentes do grupo 2 houve diferenças nos resultados, os quais podem ser explicados devido à diferença de potência na ducha, já que o aluno 1 gastou 6 litros por minuto, o aluno 2 usou 9 litros por minuto e, por fim, o aluno 3, consumiu 4,5 litros por minuto. Cabe

ISSN 1982-4866. Revista Dynamis. FURB, Blumenau, v. 24, n.1, p.77-93, 2018. 
salientar que essa averiguação de água "desperdiçada" por cada aluno foi calculada usando-se uma bacia depositada no piso do banheiro e abrindo o chuveiro. Assim investigaram a quantidade de litros que saía por minuto e multiplicaram pelo tempo do banho de cada um. Embora não tenham escrito formalmente o modelo matemático em seu relatório, relataram oralmente na apresentação dos resultados como realizaram o cálculo. Observou-se a emergência de uma equação, a qual pode-se inferir como:

$$
\text { Desperdício da água = quantidade de } \frac{\text { litros usados }}{\text { minuto }} \text { X tempo de abertura do chuveiro }
$$

Acerca dos modelos emergentes, pôde-se constatar a representação dos resultados na forma de tabelas e cálculos. Ainda, oralmente, os alunos expressaram a equação matemática acima. Segundo Almeida, Silva e Vertuan (2013), atividades de modelagem matemática favorecem a inserção de diferentes registros de representação, embora esta seja uma tarefa não espontânea dos alunos. Em outras palavras, é necessário o professor auxiliar nesse processo, questionando os alunos acerca dessa escrita. Esta atividade também propiciou aos alunos um olhar sociocrítico (BARBOSA, 2003, 2006, 2008) quando ao finalizar seus estudos, buscaram informações junto à Organização das Nações Unidas (ONU), acerca da quantidade de água necessária para cada pessoa por dia. Segundo este órgão, há uma necessidade de 110 litros diários, incluindo a higiene. A partir desta informação observaram que um dos colegas costumava exceder o tempo de banho, sendo necessário, por conscientização deste, reduzir o tempo para se enquadrar nos padrões anunciados. Ao final, comentaram que o trabalho lhes demonstrou a importância da água para a população juntamente com suas necessidades diárias, bem como a relevância de se evitar o desperdício da mesma.

Já o objetivo geral do terceiro grupo, cujo subtema denominou-se "Crosta branca: saúde e riscos à saúde pública", tratou da compreensão da formação da crosta branca nos utensílios domésticos e os riscos dela para a saúde. A professora dos alunos possibilitou aos alunos investigações em sites os quais mostraram, segundo interpretações dos alunos, que a crosta branca não é prejudicial à saúde devido a sua composição de carbonato de cálcio e magnésio.

O grupo também apresentou uma hipótese de como a crosta branca poderia se formar em utensílios, quando a água é aquecida ou quando esta fica depositada em algum recipiente. Ademais, os integrantes promoveram, em conjunto com os professores do grupo de pesquisa, uma experiência em laboratório que representava a formação da crosta branca em um copo de béquer utilizando-se do aquecimento de uma solução saturada em carbonato de cálcio. Também realizaram uma entrevista com uma fiscal de saúde do município de residência, na qual se interessaram em saber quais eram as substâncias presentes na água do seu município, sendo elas cal, cloro e flúor.

Ao final do estudo, os alunos concluíram que a crosta nada mais é do que calcário depositado. Tomaram conhecimento das substâncias presentes na água de seu município, a formação da crosta branca nos utensílios domésticos e as providências a serem tomadas para que a mesma não se forme nesses recipientes. Como se pode observar, neste grupo não houve a emergência de modelos matemáticos, mas sim a discussão de temas extramatemáticos como propõem Almeida, Silva e Vertuan (2013). Para os alunos, estes assuntos foram representativos, pois estavam relacionados à sociedade na qual os alunos estão inseridos.

O quarto grupo, com o subtema "Localização e perfuração de poços em nosso município", propôs como objetivo a investigação da localização dos poços artesianos, assim como a compreensão do processo de perfuração desses poços. A escolha do assunto foi

ISSN 1982-4866. Revista Dynamis. FURB, Blumenau, v. 24, n.1, p.77-93, 2018. 
motivada, segundo os integrantes desse grupo, "porque ele é pouco comentado e tem um grau de dificuldade no acesso às informações. Nossa motivação foi trazer para os colegas informações relacionadas com o assunto" (GRUPO 4).

Inicialmente o grupo realizou pesquisas na internet buscando informações acerca de perfurações. Após, realizaram uma entrevista com funcionários da prefeitura e tomaram conhecimento de que o próprio município é responsável pelos poços da cidade, sendo que contam com a assistência técnica de uma empresa a qual realiza o tratamento e a limpeza da água. Também adquiriram informações como a vazão e a quantidade de água liberada em alguns poços, sendo que o poço de maior vazão é o que fornece 10.000 litros/hora, equivalendo a 207.000 litros/dia. Isso significa que o poço opera mais de 20 horas diárias. Para ilustrar o posicionamento dos poços, o grupo localizou-os no Google Maps $^{2}$ e demonstraram-nos numa maquete, conforme Figura 4.

Figura 4 - Localização de poços no centro da cidade.

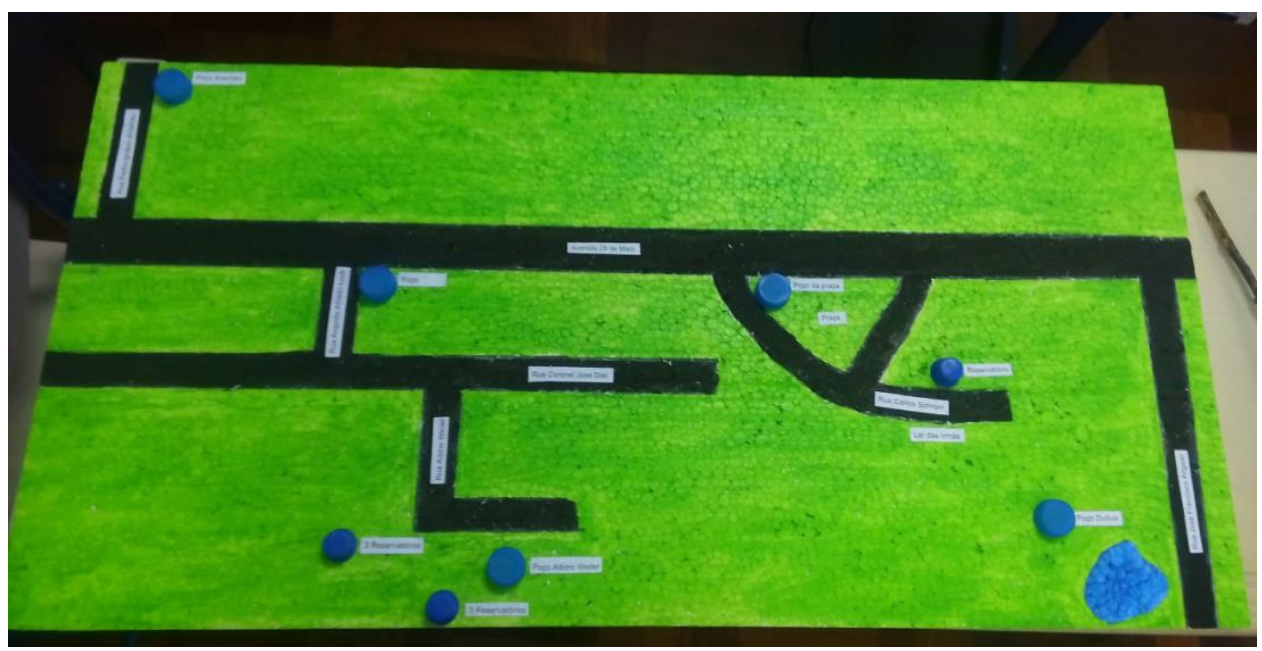

Fonte: Dos autores (2016).

Esse grupo também recebeu a informação, junto à prefeitura, de que antigamente os poços eram localizados usando-se "forquilhas de pessegueiro". Segundo uma antiga senhora que os alunos entrevistaram, a forquilha era

[...] uma espécie de graveto em forma de Y, com os galhos de pessegueiros. Após a forquilha estar pronta, deixavam uma ponta [...] para frente e seguravam com as mãos as outras duas extremidades do graveto, e iam à procura de água. Se a ponta [...] balançava ou abaixava, era sinal de que havia água no local, e lá era feito um poço. A tática era muito boa, e funcionava muitas vezes, mas nem sempre o sucesso era garantido (NARRATIVA DO GRUPO 4, A PARTIR DA ENTREVISTA REALIZADA COM A MORADORA DA CIDADE, 2016).

Neste grupo os modelos foram evidenciados por meio de maquetes e desenhos contemplando a localização dos poços. Os alunos ainda mencionaram que tiveram que "transferir as informações do Google Maps para o desenho", o que explica a conversão de dados realizados em certa escala.

${ }^{2}$ https://www.google.com.br/maps/

ISSN 1982-4866. Revista Dynamis. FURB, Blumenau, v. 24, n.1, p.77-93, 2018. 
O quinto grupo propôs o subtema "Funcionamento das bitolas" e abordou o assunto exemplificando algumas informações técnicas das bitolas como sua classificação, diâmetro, os tipos e o material de fabricação. Juntamente com essas informações pesquisadas na internet, o grupo buscou também dados em entrevistas com funcionários de três lojas de materiais de construção diferentes. Nessa entrevista, elaboraram um questionário com 11 questões abordando quais os tipos de canos e quais os diâmetros mais utilizados com suas conversões. $\mathrm{O}$ grupo organizou uma tabela com base nas respostas dos funcionários referente às bitolas dos canos, em polegadas e milímetros. O Quadro 2 ilustra as bitolas mais utilizadas, conforme mencionado pelos entrevistados.

\section{Quadro 2 - Quadro de equivalência construído pelos alunos relacionando bitolas em polegadas e em milímetros, segundo a ABNT}

\begin{tabular}{|c|c|}
\hline $\begin{array}{c}\text { Diâmetro em } \\
\text { Polegada }\end{array}$ & $\begin{array}{c}\text { Diâmetro em } \\
\text { milímetros }\end{array}$ \\
\hline $1 / 2$ & 15 \\
\hline $3 / 4$ & 20 \\
\hline $1 \frac{1}{4} 4$ & 32 \\
\hline $1 \frac{1}{2}$ & 40 \\
\hline 2 & 50 \\
\hline
\end{tabular}

Fonte: Grupo de alunos 5.

Ao final, o grupo concluiu que os tipos de canalizações mais utilizadas em sua cidade são as soldáveis e as de esgotos. Os canos de PVC podem transportar água a uma temperatura máxima de $20^{\circ} \mathrm{C}$, enquanto que os de metais cromados a $70^{\circ} \mathrm{C}$. Constataram, também que, em uma ligação da caixa de água até a casa são utilizados tipos de canos de PVC com bitolas de 20 a 25 milímetros.

Novamente houve a emergência de temas extramatemáticos (ALMEIDA, SILVA e VERTUAN, 2013), junto com o conteúdo matemático sobre medidas, conversões e unidades. Segundo os alunos, "bitolas" era um assunto que eles tinham ouvido falar, mas que foi difícil compreender como isso funcionava. Pode-se inferir que a dificuldade pode estar relacionada ao fato de que a canalização com suas referidas bitolas estarem, na maioria das vezes, em locais não visíveis. É possível supor, ainda, que este tema não é algo do cotidiano dos alunos, pois vazamentos nas suas residências são resolvidos pelos seus pais ou por profissionais da área.

Por sua vez, o sexto grupo, cujo subtema foi "Recolhimento e reaproveitamento da água", apresentou uma questão norteadora que abrangeu a captação da água da chuva e reutilização da água consumida no município. O grupo descreveu, inicialmente, de forma genérica, alguns métodos de reaproveitamento da água pesquisados em outros estudos realizados por pesquisadores e que estavam disponíveis na internet. Conseguinte, realizou uma entrevista com funcionário da prefeitura para responder a questão norteadora, concluindo que ainda não há um método de recolhimento da água da chuva implantado, porém há um projeto 
que visa à reutilização da água da chuva em todos os prédios da cidade. Além disso, o grupo confeccionou um cartaz para conscientizar os moradores sobre a questão.

O grupo concluiu que

Este trabalho nos proporcionou um grande aprendizado e que devemos assim que possível e possuir condições financeiras recolher e reaproveitar a água da chuva. Se não começarmos logo a reaproveitar a água nossos netos e talvez nossos filhos irão sofrer com a escassez de água potável (GRUPO 6).

Já o sétimo grupo escolheu como subtema "Custos da água". Inicialmente os componentes apresentaram um quadro para o cálculo da conta de água em diferentes situações, sendo elas comercial e residencial. Após analisar o quadro oferecido pela prefeitura, os alunos realizaram pesquisas em sites da internet e realizaram uma entrevista com um funcionário da prefeitura, momento esse em que adquiriram dados como a taxa fixa do custo da água de sua cidade, bem como informações referentes a valores para cada metro cúbico de água consumido. Além disso, o grupo recebeu uma tabela da prefeitura referente aos poços, constando vazão média, potência das bombas, expressas em HP, consumo médio e custo médio por metro cúbico. A partir da leitura concluíram que a taxa de expediente do documento é de $\mathrm{R} \$ 3,04$ e que o custo a ser pago por alguém que gasta até $12 \mathrm{~m}^{3}$ era de $\mathrm{R} \$ 26,78$. Aqui esperava-se que o grupo chegasse num modelo correspondente ao custo total, incluindo o custo de expediente e o valor por metro cúbico. Pode-se inferir que isso possa não ter ocorrido pelo fato de os alunos, até aquele momento, ainda não terem trabalhado na perspectiva da Modelagem Matemática. Segundo Biembengut e Hein (2003), em escolas que seguem um currículo regular, é mais difícil ocorrer o desenvolvimento desta metodologia.

Os alunos concluíram que foi significativa sua aprendizagem sobre os custos da água, como a taxa mínima a ser paga, funcionamento do hidrômetro e o cálculo do pagamento da conta de água. Porém, nem todos os objetivos a que eles se propuseram foram concretizados, conforme mencionaram. Acredita-se que os próprios alunos queriam ter obtido algum modelo matemático, mas este não emergiu, apesar das mediações da professora.

O oitavo grupo propôs como objetivo descobrir como é realizado o tratamento da água no município e escolheu como subtema "Tratamento da água". Com base na busca por informações na internet, inicialmente, o grupo de alunos apresentou os processos de tratamento em que a água passa antes de chegar à casa do morador, concluindo que esta é a principal forma de prevenir doenças relacionadas à mesma. Além disso, mencionaram que a falta de água potável acarreta em 1,8 milhões de mortes infantis no mundo. O grupo também realizou uma entrevista com um funcionário da prefeitura que falou sobre os procedimentos físicos e químicos que a água passa para seu tratamento, dando ênfase à adição de cloro. "Com essa pesquisa chegamos à conclusão de que para que possamos utilizar a água, ela precisa ser tratada, porém, devemos tomar alguns cuidados no nosso dia a dia, pois ela possui alguns produtos químicos que podem causar diversas doenças", concluiu o Grupo 8.

Quanto aos modelos matemáticos, não foi possível observar evidências de registros, seja em forma de tabelas, gráficos, equações ou outro formato. A preocupação do grupo estava mais voltada à descrição das etapas de tratamento da água. Aqui esperava-se que o grupo de alunos estabelecesse uma relação de quantidade de quilograma de cloro por litros de água, fato esse que não ocorreu também. Portanto, não foi possível evidenciar um modelo matemático propriamente dito, mas outros assuntos relevantes para o grupo foram discutidos. 
Por fim, o nono grupo escolheu como temática as doenças transmitidas pela água, propondo o subtema "Doenças da água". Os alunos descreveram, inicialmente, as principais doenças e os sintomas delas. Além da pesquisa realizada em sites para obter as informações técnicas sobre as doenças, o grupo realizou uma entrevista com funcionários do posto de saúde, levando-os a concluir que a principal doença é a diarreia aguda.

A preocupação do grupo estava mais voltada ao tema saúde e não para cálculos em si. Em seu relatório, o grupo comenta dificuldades na realização e organização do trabalho, porém houve dedicação por parte dos integrantes, realizando-o da melhor maneira possível.

Analisando-se os resultados dos nove grupos, pode-se observar que houve a emergência de algum tipo de modelo matemático nos grupos 1, 2, 4, 5 e 7. Estes foram representados por meio de maquetes, desenhos, gráficos e uma equação que foi mencionada oralmente. Já os grupos 3, 6, 8 e 9 problematizaram outros aspectos e não conseguiram realizar registros matemáticos que relacionassem a Matemática às suas situações-problema.

\section{CONSIDERAÇÕES FINAIS}

Com base nos relatórios e nos diários de bordo entregues pelos alunos, verificou-se as informações que foram coletadas por cada grupo, as dificuldades que emergiram durante a realização da pesquisa, os materiais coletados, as novas experiências vivenciadas, as expectativas perante o novo e a disposição em participar da prática. Cabe salientar que esta foi a primeira experiência dos alunos e da professora titular com a metodologia da Modelagem Matemática. Em adição, explicita-se que a professora desenvolveu esta prática no nível III, de acordo com Barbosa (2001), quando os alunos, a partir de um tema gerador, propõem uma situação-problema, coletam as informações e apresentam uma solução para o problema. Ainda para Barbosa (2001), os professores quando iniciam as práticas de Modelagem Matemática sentem-se um pouco inseguros, necessitando orientação, o que também ocorreu no nosso grupo de pesquisa.

Quanto aos modelos que os alunos usaram para representar as situações-problema, estes foram em formato de desenhos, maquetes, tabelas, gráficos e uma equação que não foi escrita, mas citada oralmente quando da apresentação do trabalho. Desta forma, foi possível observar também neste trabalho a emergência de diferentes possibilidades de representação dos modelos matemáticos, como sugerem Biembengut (2014) e Almeida, Silva e Vertuan (2013).

Pode-se observar, ainda, a emergência de outros assuntos que não fizeram uso da Matemática. No entanto, é relevante o aluno discutir e problematizar questões sociais que emergem da sociedade na qual estão inseridos, ou seja, temas extramatemáticos também podem ser abordados e discutidos na sala da aula, com vistas a tornar o aluno um cidadão crítico e reflexivo, como apregoa o documento que rege o Ensino Médio Politécnico, contribuindo, assim, para o exercício pleno da cidadania.

No que tange aos participantes dos grupos, a análise dos dados coletados revelou o quanto o uso de uma atividade de Modelagem Matemática contrubuiu na motivação para aprender Matemática. Segundo os estudantes, eles se sentiram motivados a aprender matemática devido à atividade ser de forma contextualizada utilizando temas da sua realidade e de seu interesse. Ainda apresentaram habilidades como a capacidade de colaboração com os colegas ao trabalharem em grupo.

ISSN 1982-4866. Revista Dynamis. FURB, Blumenau, v. 24, n.1, p.77-93, 2018. 
Por fim, sugere-se que a professora titular da turma continue desenvolvendo práticas de Modelagem Matemática, pois é modelando que se aprende a modelar. É um processo, portanto, exige ação, reflexão e nova ação, de forma contínua.

\section{REFERÊNCIAS}

ALMEIDA, Lourdes Maria Werle; BRITO, Dirceu dos Santos. Atividades de modelagem matemática: que sentido os alunos podem lhe atribuir? Ciência \& Educação, v. 11, n. 3, p. 483-498, 2005. Disponível em: <http://www.scielo.br/pdf/ciedu/v11n3/10.pdf >. Acesso em: 03 de abril 2015.

ALMEIDA, Lourdes Werle de; SILVA, Karina Pessôa da; VERTUAN, Rodolfo Eduardo. Modelagem Matemática na Educação Básica. São Paulo: Contexto, 2013.

BARBOSA, Joney C. Modelagem matemática e os professores: a questão da formação. Bolema, Rio Claro, n. 15, p. 5-23, 2001.

BARBOSA, J. C. Modelagem matemática e a perspectiva sócio crítica. In: SEMINÁRIO INTERNACIONAL DE PESQUISA EM EDUCAÇÃO MATEMÁTICA, 2. 2003, Santos. Anais... São Paulo: SBEM, 2003. 1 CD-ROM.

Mathematical modelling in classroom: a critical and discursive perspective.

Zentralblatt für Didaktik der Mathematik, v. 38, n. 3, p. 293-301, 2006.

As discussões paralelas no ambiente de aprendizagem modelagem matemática. Acta Scientiae, v.10, n.1, jan./jun., p. 47-57, 2008.

BASSANEZI, Rodney Carlos. Modelagem Matemática: teoria e prática. São Paulo: Contexto, 2015.

BIEMBENGUT, Maria Salett; HEIN, Nelson. Modelagem Matemática no ensino. São Paulo: Contexto, 2003.

Modelagem Matemática no Ensino. São Paulo: Contexto, 2007.

BIEMBENGUT, Maria Salett. Modelagem Matemática \& Resolução de Problemas, Projetos e Etnomatemática: Pontos Confluentes. ALEXANDRIA Revista de Educação em Ciência e Tecnologia, v.7, n.2, p. 197-219, 2014.

BLUM, W.; FERRI, R. B. Mathematical modelling: can I be taught and learnt? Journal of mathematical modeling and application, Blumenau, v. 1, n. 1, p. 45-58, 2009.

BURAK, Dionísio. A modelagem matemática e a sala de aula. In: I ENCONTRO PARANAENSE DE MODELAGEM EM EDUCAÇÃO MATEMÁTICA - I EPMEM. Anais ... Londrina, 2004. 
BURAK, Dionísio; ARAGÃO, Rosália M. R. A modelagem matemática e relações com a aprendizagem significativa. 1. Ed. Curitiba: Editora CRV, 2012.

GOLDENBERG, Mírian. A arte de pesquisa: Como fazer pesquisa qualitativa em Ciências Sociais. Rio de Janeiro: Record, 2013.

KLÜBER, Tiago Emanuel; BURAK, Dionísio. Concepções de modelagem matemática: contribuições teóricas. Revista Educação Matemática e Pesquisa. São Paulo, v. 10, n. 1, pp. 17-34, 2008. Disponível em:

<http://revistas.pucsp.br/index.php/emp/article/viewFile/1642/1058>. Acesso em: 15 de maio de 2015.

MOREIRA, Herivelto; CALEFFE, Luiz G. Metodologia da pesquisa para o professor pesquisador. 2 ed. - Rio de Janeiro: Lamparina, 2008.

RIO GRANDE DO SUL/SE - Secretaria da Educação do Estado do Rio Grande do Sul. Ensino Médio. Disponível em:

<www.educacao.rs.gov.br/pse/html/ens_medio.jsp?ACAO=acao1> Acesso em: 08 jan. 2015.

RIO GRANDE DO SUL. Secretaria de Estado da Educação. Regimento Padrão Ensino Médio Politécnico. Disponível em:

$<$ http://servicos.educacao.rs.gov.br/dados/ens_med_regim_padrao_em_Politec_I.pdf $>$. Acesso em 18 jun 2018.

SILVA, D. K.; DALTO, J. O. Modelagem matemática na formação de professores: compartilhando uma experiência. In: ALMEIDA, L. M. W.; ARAÚJO, J. L.; BISOGNIN, E. (Org.). Práticas de modelagem matemática na Educação Matemática. Londrina, PR: Eduel, p. 181-200, 2011. 